\title{
In Vitro Gap Changes After Porcelain Firing Cycles of Three and Four Unit of CAD/CAM Milling, Laser Sintering and Cast Metal Ceramic
} Restorations

\author{
Muhammed Abdullah Keles ${ }^{1}$ (D), Sebnem Begum Turker $^{2}$ (i) \\ ${ }^{1}$ Private Dentist, Istanbul, Turkey. \\ ${ }^{2}$ Marmara University, Faculty of Dentistry, Department of Prosthodontics, Istanbul, Turkey. \\ Correspondence Author: Sebnem Begum Turker \\ E-mail: begumturker@hotmail.com \\ Received: $12.06 .2018 \quad$ Accepted: 25.09.2018
}

\begin{abstract}
Objectives: Marginal adaptation changes during the veneering process is an important factor in the clinical success of metal framework techniques such as conventional cast metal cores (LW), CAD-CAM Metal Milling (MM) and Direct Metal Laser Sintering (DMLS). The aim of this study is to evaluate the marginal fit changes between three- and four- unit's metal ceramic fixed partial dentures (FPD's) fabricated by Lost Wax (LW), CAM Metal Milling (MM) and (Direct Metal Laser Sintering) DMLS metal framework techniques after porcelain firing cycles (PFC).

Methods: A total of 60 stainless steel three and four unit FPD's models were fabricated. Specimens were randomly divided into three groups to fabricate metal ceramic FPD's frameworks with LW, MM and DMLS techniques. Before and after PFC, cross-sections from silicone replicas were obtained, sectioned, examined and measured with a light microscope. The statistical analysis was done with Mann-Whitney U and Kruskal Wallis and Wilcoxon Signed Ranks tests. Results were evaluated at $95 \%$ of confidence interval and $p<0.05$ level.

Results: There was a statistically significant difference between the three and four unit of FPD's, before PFC for LW and MM (p:0.000) and DMLS ( $p: 0.019)$ 's groups and only DMLS ( $p: 0.006)$ 's group was statistically significant after PFC. The mean marginal gaps of LW technique was higher than the MM and DMLS's techniques before PFC. After PFC, DMLS's technique results were higher than LW and MM technique but, no statistically significant difference was found between the marginal gap values of the three and neither for four units of DMLS's FPD's.

Conclusion: PFC decreases the mean marginal gap of the LW and MM group, but, there was a slight increase for DMLS group. However, all the marginal gap values obtained were in clinical acceptance level for three and four-units FPD's for all tested specimens.

Keywords: Marginal gap, lost wax, CAD/ CAM, laser sintering, porcelain firing cycle
\end{abstract}

\section{INTRODUCTION}

In 21th century, metal fused to porcelain restorations were usually used in clinical practice and are still a gold standard in fixed partial dentures. The success of fixed partial dentures (FPDs) depends a lot of factors (1). Marginal fit plays an important role for a dental restoration. The degradation of cement in oral cavity can result in loss of marginal seal, retention of plaque, development of secondary dental caries and development of periodontal disease (2). McLean and von Fraunhofer (3) suggested that the maximum gap should be $120 \mu \mathrm{m}$. Goldin et al (4) reported that the clinically acceptable marginal gap should be between 40-120 $\mu \mathrm{m}$.

Metal ceramic restorations can be fabricated from the noble and non-noble alloys. Non-noble alloys ( $\mathrm{Ni}-\mathrm{Cr}$ and $\mathrm{Co}-\mathrm{Cr}$ alloys) were used instead of noble alloys due their lower cost $(5,6)$. Because of the allergic reactions to $\mathrm{Ni}-\mathrm{Cr}$ alloys, more biocompatible Co-Cr alloys were developed (7). Lots of technique are available for producing $\mathrm{Co}-\mathrm{Cr}$ copings. CAD/CAM systems were developed and it was a possible alternative to conventional lost-wax technique (LW). Milling the frameworks from a block of $\mathrm{Co}-\mathrm{Cr}(\mathrm{MM})$ and sintering metal powders by using direct metal laser sintering (DMLS) were two fabrication methods of digitized technique (8). Short manufacturing time, elimination of casting shrinkage and easy production of complicated shapes were the advantages of $\operatorname{CAD} / C A M$ techniques $(9,10)$. CAD/CAM restorations can be affected by precision of scanner, precision of milling machine and data transformation process (11) Gonzalo et al. (12) reported that better marginal fit values with CAD/CAM processing of ceramic systems than with the conventional LW technique. Sundar et al (10), Xu et al. (13)' Kim et al. $(14,15)$ reported that metal copings manufactured by DMLS showed good marginal fit. Kane et al. (16) pointed out that MM Co-Cr copings (NobelProcera; Nobel Biocare) were shown clinically acceptable marginal fit in the range of 52-113 $\mu \mathrm{m}$.

The major problem with metal ceramic restorations is the marginal fit. The marginal fit changes during the ceramic firing is a big problem for the metal ceramic restorations (17). The contraction occurred due to the porcelain firing cycles, margin and alloy type are important factors contributing to distortion. Sundar et al (10) reported that ceramic firing procedure has minimal effect on metal laser sintered crowns. The aim of this study was to evaluate and to compare the changes on the marginal gaps of three and four-unit posterior metal ceramic restorations fabricated by using three different techniques as conventional LW, MM and DMLS after PFC. The 
null hypotheses was that the marginal fit changes during the firing cycles will be less in MM and DMLS's than the LW's technique for the three and four-units FPD'S.

\section{MATERIALS AND METHODS}

Three different techniques as conventional LW, MM and DMLS were chosen for evaluation. Materials used in this study were shown in Table 1.

Table 1. Materials tested

\begin{tabular}{|c|c|c|c|}
\hline Material & $\begin{array}{l}\text { Product Name } \\
\text { (Manufacturer) }\end{array}$ & Ingredient's & $\begin{array}{l}\text { Batch } \\
\text { number }\end{array}$ \\
\hline $\begin{array}{l}\text { Impression } \\
\text { Material }\end{array}$ & $\begin{array}{l}\text { Panasil Putty Soft } \\
\text { (Kettenbach, California, } \\
\text { USA) } \\
\end{array}$ & $\begin{array}{l}\text { Polyvinlysiloxane } \\
\text { additional silicon }\end{array}$ & 11121 \\
\hline $\begin{array}{l}\text { Impression } \\
\text { Material }\end{array}$ & $\begin{array}{l}\text { Panasil Initial Contact } \\
\text { Light (Kettenbach, } \\
\text { California, USA) }\end{array}$ & $\begin{array}{l}\text { Polyvinlysiloxane } \\
\text { additional silicon }\end{array}$ & 13411 \\
\hline $\begin{array}{l}\text { Impression } \\
\text { Material }\end{array}$ & $\begin{array}{l}\text { Panasil Initial Contact } \\
\text { X-Light (Kettenbach, } \\
\text { California, USA) }\end{array}$ & $\begin{array}{l}\text { Polyvinlysiloxane } \\
\text { additional silicon }\end{array}$ & 13401 \\
\hline Metal & $\begin{array}{l}\text { Magnum Ceramic S } \\
\text { (Mesa, Brescia, Italy) }\end{array}$ & $\begin{array}{l}\text { Metal blocks (Ni, } \\
\text { Cr and } \mathrm{Mo} \text { ) }\end{array}$ & 0546 \\
\hline Metal & $\begin{array}{l}\text { Yena CoCr } 10 \mathrm{~mm} \\
\text { (Yenadent, Istanbul, } \\
\text { Turkey) }\end{array}$ & $\begin{array}{l}\text { Metal blocks (Co, } \\
\text { Cr and Mo) }\end{array}$ & \\
\hline Metal & $\begin{array}{l}\text { EOS CobaltChrome SP2 } \\
\text { (EOS, Munich, Germany) }\end{array}$ & $\begin{array}{l}\text { Metal blocks (Co, } \\
\text { Cr and Mo) }\end{array}$ & $\begin{array}{l}9011- \\
0018\end{array}$ \\
\hline Wax & $\begin{array}{l}\text { Waxwire (Bego, Bremen, } \\
\text { Germany) }\end{array}$ & Wax sprue & 40085 \\
\hline Wax & $\begin{array}{l}\text { Bego Kronenwachs (Bego, } \\
\text { Bremen, Germany) }\end{array}$ & Modelling wax & 40115 \\
\hline Investment & $\begin{array}{l}\text { Hera Moldavest (Heraeus, } \\
\text { Germany) }\end{array}$ & $\begin{array}{l}\text { Phosphate } \\
\text { bonded } \\
\text { investment }\end{array}$ & 66009780 \\
\hline
\end{tabular}

\subsection{Specimen preparation}

Master abutments were prepared by CNC machining (Chevalier FBL-1233, Chang Hua, Taiwan) using stainless steel with $360^{\circ} 1 \mathrm{~mm}$ rounded shoulder finish line, $10 \mathrm{~mm}$ diameter for molars and $5 \mathrm{~mm}$ for premolars, $5 \mathrm{~mm}$ axial height, $10 \%$ axial taper, and flat occlusal surface (18). Prepared master abutments were fixed on a metal plate using screws to obtain three - and four-unit FPD's framework. (Fig.1 and Fig.2).

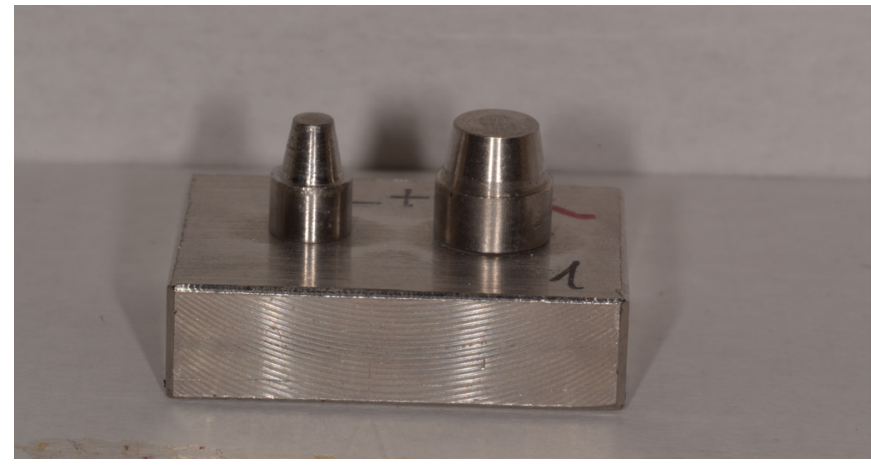

Figure 1. Three-units master abutments

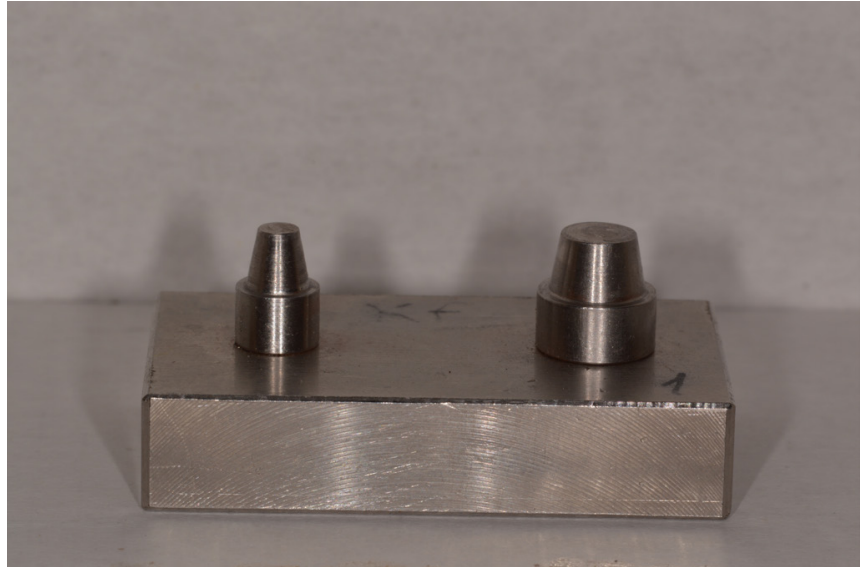

Figure 2. Four-units master abutments

In total of 30 three-unit and 30 four-unit FPDs were fabricated with LW, MM and DMLS's techniques ( $\mathrm{n}: 10)$.

Conventional lost-wax method (LW) (Group 1) (n:10): Two layers of die spacer $(30 \mu \mathrm{m})$ (Isowachs, Labor - Scheftner, Mainz, Germany) were applied on each metal abutments specimens to eliminate the dimensional stability problem caused by the impression material. To fabricate a $0.4 \mathrm{~mm}$. uniform thickness of coping, pattern wax (Bego Kronenwachs, Bego, Bremen, Germany) was used. The thicknesses of patterns were checked by using a metal gauge. A sprue was attached to the completed wax coping (Waxwire, Bego, Bremen, Germany), invested (Hera Moldavest,,Heraeus, Gerrmany) and casted with Ni-Cr alloy pellets (Mesa Magnum Ceramic S, Brescia,Italy). All the casting were performed according to the manufacturers' instructions.

Metal Milling technique (MM) (Group 2) ( $\mathrm{n}: 10)$ : 3D laser scanner (D800; 3Shape A/S, Copenhagen, Denmark).was used to scan each metal model and CAD software program (Dental DesignerTM; 3Shape A/S, Copenhagen, Denmark) was used to design the coping with $0.4 \mathrm{~mm}$ in thickkness. The internal space was set $30 \mu \mathrm{m}$ from the $1 \mathrm{~mm}$ upper margin. The completed design was saved as an STL file and send to the milling machine (Yenamak D40, Yenadent, Istanbul, Turkey) to mille the Co-Cr alloy copings with metal blocks (Yenadent, Istanbul, Turkey).

Direct metal laser sintering (DMLS) (Group 3) (n 10): Metal laser sintering technology (EOS M270) (EOS, Munich, Germany) was used to fabricate $0.4 \mathrm{~mm}$ in thickness with internal relief of $30 \mu \mathrm{m}$ specimens with a biocompatible $\mathrm{Co}-\mathrm{Cr}$ alloy in powder form, designed specifically for metal porcelain restorations. (EOS CobaltChrome SP2, Munich, Germany). 3D scanner (Scanner 7Series) (Dental Wings 7Series 3D Scanner, Montreal, Canada) was used to scan the die specimens. The CAD design of the coping was obtained as an STL data which was used in EOS RP tools software (EOS RP Tools; Magics RP, Munich, Germany) for fabrication of copings.

Vita VMK Master (Vita Zahnfabrik, Bad Sackingen, Germany) and Vita VMK 95 Metall Keramik Dentine, (Vita Zahnfabrik, 
Bad Sackingen, Germany) were used as veneering material for all groups.

\subsection{Marginal gap evaluation}

Marginal gap values were measured at two different times. The initial measurement was performed before and the second and final measurement was measured after the ceramic firing cycles. Any internal adjustments were done after ceramic firing cycles for each tested specimens.

The silicone replica technique was used (Panasil Kettenbach, California, USA) to observe and compare the marginal gap changes between the initial and final measurements. The frameworks of the FPDs were filled with extra light body silicone impression material (Panasil Initial Contact X - Light Kettenbach, California, USA); then were placed onto the metal abutments specimens. Finger pressure was used during setting of the silicone impression material. Then, thin silicone film replicas and copings were removed together from the abutments. To stabilize the silicone films representing the space between abutment teeth and frameworks, a light body silicone (Panasil Initial Contact Light Kettenbach, California, USA) was injected on the light body silicone replicas and immediately during working time, retainers put into boxes filled with heavy body silicone (Panasil Putty Soft Kettenbach, California, USA).

Silicone replicas were sectioned in both of the mesio-distal and bucco-lingual directions in one time with a razor blade. Initial and final silicone replicas were examined under a binocular stereomicroscope (Leica Optic microscope, Leica Cambridge Ltd., Cambridge, England) at a magnification of $\times 48$ to obtain marginal gap values. From each segment, 9 different marginal gap values were measured. A total of 36 measurements were obtained per one abutment (Fig.3).

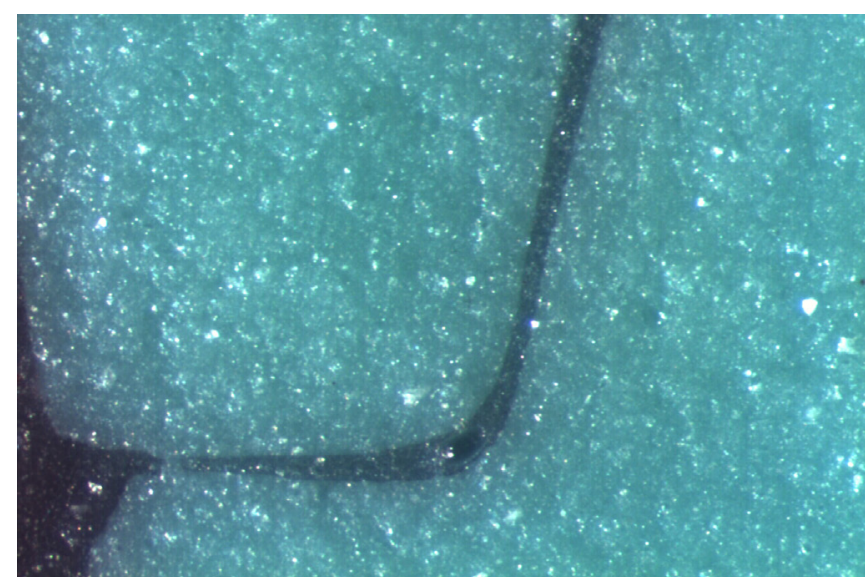

Figure 3. Stereomicroscope image of marginal gaps measurements points

\subsection{Statistical analyses}

SPSS for Windows, version 15.0 (SPSS Inc., Chicago, IL, USA) was used for the statistical analysis. To compare quantitative data without normal distribution, for two groups MannWhitney $U$, for more than two groups Kruskal Wallis test were used. Wilcoxon Signed Ranks tests were used for the statistical analysis of intra-group comparison of non-normal distribution parameters. The results were evaluated in $95 \%$ confidence interval $(p<.001)$

\section{RESULTS}

The minimal, maximal and mean marginal gap values of the three and four - unit FPD's for LW, MM and DMLS's groups and the Mann - Whitney $U$ statistical analysis results were shown in Table 2. Tables 3 shows the comparison of three and four units FPD's. The Wilcoxon Signed Range test results were given in Table 4.

Statistically significant difference was found between the three and four-unit of FPD's, before porcelain firing process for LW (p:0.000) and MM (p:0.000) and DMLS (p:0.019)'s groups and only DMLS (p:0.006)'s group was statistically significant after PFC. Mean marginal gap values of three and four-units FPD's fabricated by LW, MM and DMLS before PFC for three and four-units were $98.68 \mu \mathrm{m}$, and $68.72 \mu \mathrm{m}$; $82.74 \mu \mathrm{m}$ and $71.10 \mu \mathrm{m} ; 63.97 \mu \mathrm{m}$ and $70.42 \mu \mathrm{m}$ and after porcelain firing cycle $64.58 \mu \mathrm{m}$ and $65.70 \mu \mathrm{m} ; 63.69 \mu \mathrm{m}$ and $61.95 \mu \mathrm{m} ; 64.27 \mu \mathrm{m}$ and $71.64 \mu \mathrm{m}$ respectively.

Table 2. The mean marginal gap values of the three and four - unit fixed partial dentures for LW,MM and DMLS group $\left({ }^{*} p<0,05\right)$

\begin{tabular}{|c|c|c|c|c|c|c|c|c|}
\hline & & & $\mathrm{N}$ & Min & Max & Mean & SD & $p$ \\
\hline \multirow{4}{*}{$\begin{array}{l}\text { LW } \\
\text { Group } 1\end{array}$} & \multirow{2}{*}{$\begin{array}{l}\text { Before } \\
\text { porcelain } \\
\text { firing cycles }\end{array}$} & $\begin{array}{l}\text { Three- } \\
\text { unit }\end{array}$ & 10 & 21.96 & 306.72 & 98.68 & 28.94 & \multirow{2}{*}{$0.000 *$} \\
\hline & & $\begin{array}{l}\text { Four- } \\
\text { unit }\end{array}$ & 10 & 13.49 & 136.14 & 68.72 & 10.27 & \\
\hline & \multirow{2}{*}{$\begin{array}{l}\text { After } \\
\text { porcelain } \\
\text { firing cycles }\end{array}$} & $\begin{array}{l}\text { Three- } \\
\text { unit }\end{array}$ & 10 & 17.49 & 115.56 & 64.58 & 8.34 & \multirow{2}{*}{0.589} \\
\hline & & $\begin{array}{l}\text { Four- } \\
\text { unit }\end{array}$ & 10 & 13.13 & 105.12 & 65.70 & 5.86 & \\
\hline \multirow{4}{*}{$\begin{array}{l}\text { MM } \\
\text { Group } 2\end{array}$} & \multirow{2}{*}{$\begin{array}{l}\text { Before } \\
\text { porcelain } \\
\text { firing cycles }\end{array}$} & $\begin{array}{l}\text { Three- } \\
\text { unit }\end{array}$ & 10 & 28.75 & 161.88 & 82.74 & 11.28 & \multirow{2}{*}{$0.000 *$} \\
\hline & & \begin{tabular}{|l} 
Four- \\
unit
\end{tabular} & 10 & 20.86 & 120.60 & 71.10 & 5.02 & \\
\hline & \multirow{2}{*}{$\begin{array}{l}\text { After } \\
\text { porcelain } \\
\text { firing cycles }\end{array}$} & $\begin{array}{l}\text { Three- } \\
\text { unit }\end{array}$ & 10 & 17.15 & 104.32 & 63.69 & 6.03 & \multirow{2}{*}{0.168} \\
\hline & & $\begin{array}{l}\text { Four- } \\
\text { unit }\end{array}$ & 10 & 15.13 & 99.78 & 61.95 & 4.00 & \\
\hline \multirow{4}{*}{$\begin{array}{l}\text { DMLS } \\
\text { Group } 3\end{array}$} & \multirow{2}{*}{$\begin{array}{l}\text { Before } \\
\text { porcelain } \\
\text { firing cycles }\end{array}$} & $\begin{array}{l}\text { Three- } \\
\text { unit }\end{array}$ & 10 & 13.13 & 117.18 & 63.97 & 8.12 & \multirow{2}{*}{$0.019 *$} \\
\hline & & $\begin{array}{l}\text { Four - } \\
\text { unit }\end{array}$ & 10 & 14.55 & 119.96 & 70.42 & 9.73 & \\
\hline & \multirow{2}{*}{$\begin{array}{l}\text { After } \\
\text { porcelain } \\
\text { firing cycles }\end{array}$} & $\begin{array}{l}\text { Three- } \\
\text { unit }\end{array}$ & 10 & 15.14 & 133.06 & 64.27 & 6.14 & \multirow{2}{*}{$0.006^{*}$} \\
\hline & & $\begin{array}{l}\text { Four- } \\
\text { unit }\end{array}$ & 10 & 15.23 & 130.30 & 71.64 & 12.05 & \\
\hline
\end{tabular}


Table 3. The Kruskal Wallis statistical test result of the three-unit FPD's before and after porcelain firing cycles $\left({ }^{*} p<0,05\right)$

\begin{tabular}{|c|c|c|c|c|c|}
\hline & & & Mean & SD & $\mathbf{p}$ \\
\hline \multirow{6}{*}{3 units-FPD's } & \multirow{3}{*}{$\begin{array}{l}\text { Before porcelain firing } \\
\text { cycles }\end{array}$} & LW & 98,68 & 28,94 & \multirow{3}{*}{$0,000 *$} \\
\hline & & MM & 82,74 & 11,28 & \\
\hline & & DMLS & 63,97 & 8,12 & \\
\hline & \multirow{3}{*}{$\begin{array}{l}\text { After porcelain firing } \\
\text { cycles }\end{array}$} & LW & 64,58 & 8,34 & \multirow{3}{*}{0,994} \\
\hline & & MM & 63,69 & 6,03 & \\
\hline & & DMLS & 64,27 & 6,14 & \\
\hline \multirow{6}{*}{4 units-FPD's } & \multirow{3}{*}{$\begin{array}{l}\text { Before porcelain firing } \\
\text { cycles }\end{array}$} & LW & 68,72 & 10,27 & \multirow{3}{*}{0,780} \\
\hline & & $\mathrm{MM}$ & 71,10 & 5,02 & \\
\hline & & DMLS & 70,42 & 9,73 & \\
\hline & $\begin{array}{l}\text { After porcelain firing } \\
\text { cycles }\end{array}$ & LW & 65,70 & 5,86 & $0,001 *$ \\
\hline & & MM & 61.95 & 4.00 & \\
\hline & & DMLS & 71.64 & 12.05 & \\
\hline
\end{tabular}

Table 3 shows that there was statistically significant difference ( $p: 0.000$ ) between the technique when the three-unit FPD's compared. The mean marginal gaps of LW technique was higher than the MM and DMLS's techniques before PFC. The comparison of the mean marginal gap of the four-units FPD's revealed statistically significant difference ( $p: 0.001)$ after PFC. The DMLS's technique results were higher than LW and MM technique. There were no statistically significant difference between other cycles for three and neither four unit's technique.

Statistically significant decrease was observed between the marginal gap values of three-unit FPD's manufactured with LW and MM and also, with four-units FPD's manufactured with MM. The initial marginal gap values were higher than the final values ( $p: 0.000)$. No statistically significant difference was found between the marginal gap values of the four-units FPD's and neither for three or four units of DMLS's FPD's (Table 4).

Table 4. Wilcoxon statistical analysis's results of the all the tested group $\left({ }^{*} p<0,05\right)$

\begin{tabular}{|l|l|} 
& $\mathbf{p}$ \\
\hline$L W-3$ units-FPD's & $\mathbf{0 , 0 0 0}$ \\
\hline LW -4 units-FPD's & 0,191 \\
\hline MM -3 units-FPD's & $\mathbf{0 , 0 0 0 *}$ \\
\hline MM -4 units-FPD's & $\mathbf{0 , 0 0 0 *}$ \\
\hline DMLS -3 units-FPD's & 0,970 \\
\hline DMLS -4 units-FPD's & 0,502 \\
\hline
\end{tabular}

\section{DISCUSSION}

The null hypotheses was rejected. The marginal fit changes will be less in LW and MM than DMLS's for the three and four-unit FPD'S during the firing cycles.
Development of CAD-CAM systems is an important innovation in dentistry. CAD-CAM systems provide time reduction by eliminating many disadvantages of conventional lost wax technique such as investing and burn-out process. Precision of scanner, 3D design and the precision of fabricating machine effect marginal fit of dental restorations (19) 3D design data is saved as an STL (stereolithography) file. STL format characterizes the surface structure of a solid 3D model (20). In the literature, few studies have been reported about the marginal fit of multiple-unit FPDs $s$ fabricated by DMLS and computer-aided milling (10).

In the presented study, marginal fit of three-unit and four-unit FPDs fabricated by DMLS system using Co-Cr alloy powder and computer-aided milling system using $\mathrm{Co}-\mathrm{Cr}$ metal block was compared with that of three-unit and four-unit FPDs by the LW method using Ni-Cr alloy. Because of that $\mathrm{Ni}-\mathrm{Cr}$ alloy has been widely used for metal casting until present, as a control group Ni-Cr alloy was chosen for casting as Kim et al's $(14,15)$ and Sundar et al's (10).

In vitro studies provide optimizing and standardizing circumstances for an experimental study (21). In the literature, there were many in vitro studies which investigate marginal fit $(1,5,10)$. Regish et al. (22) fabricated a standardized metal master die simulating a prepared crown. Souza et al. (23) reported that with using rounded shoulder finish line significantly lower marginal discrepancy valueswas obtained than that of tilted and large chamfer finish lines. Tsitrou et al. (24) reported better marginal fit values with shoulder finish line than chamfer finish line. In the present study, standardized stainless steel master dies simulating prepared crowns with shoulder finish line for three-unit and four-unit FPDs were manufactured. All the FPD's restorations were prepared on the related metal models to eliminate problems could be occurred during the impressions procedures for LW's group and the scanning and designing procedures for MM and DMLS's groups and to compare the metal framework techniques. In LW group, two layers of die spacer (Isowachs, Labor - Scheftner, Mainz, Germany) were applied corresponding to $30 \mu \mathrm{m}$ which was the relief area of the MM and DMLS group.

The number of data is important for the evaluation of marginal gap values. The number of measurements per crown and specimens size used in the literature has varied considerably (25-27). In some studies, measurements numbers are between 4 and 12 and this might be misleading $(26,28,29)$. Groten et al. (30) reported that number of measurements per specimen should be minimum 20-25 and ideally 50 . For the reliability of measurement, in the presented study before and after ceramic firing stage, 36 measurements were performed for each specimen, totally 72 measurements performed.

In the literature, different techniques were used to measure marginal fit of dental restorations; silicone replica, crosssectioning, direct-view, profilometry and micro CT (31). Quante et al. (32) used a silicone replica technique to examine the gaps of $\mathrm{Co}-\mathrm{Cr}$ copings under a microscope. Many researches (33-36) have used the silicone replica 
technique for the marginal fit study's. It is a non-destructive technique and it has a good reliability and precision. Örtrop et al. (5) used a stereomicroscope and digital photos to evaluate the marginal and internal gaps of $\mathrm{Co}-\mathrm{Cr}$ three-unit bridges for posterior teeth. Reich et al. (34) and Harish et al. (37) used light microscope with $\times 48$ magnification to take images. In the presented study, the silicone replica and the stereomicroscope (Leica Optic microscope, Leica Cambridge Ltd., Cambridge, England) at $\times 48$ magnification was used to evaluate the marginal gap measurements.

Dental restorations must have a good marginal fit to be clinically successful (38). In the presented study, all marginal gap measurements were within the clinically acceptable range as reported in many studies $(3,39)$. According to the three-unit FPDs results of the current study, before porcelain firing stage, mean marginal fit of DMLS $(63,97 \mu \mathrm{m})$ was less than the mean marginal fit of $\operatorname{LW}(98,68 \mu \mathrm{m})$ and MM $(82,74$ $\mu \mathrm{m})$. After porcelain firing stage, higher mean marginal fit values were observed in $\operatorname{LW}(64,58 \mu \mathrm{m})$, compared to MM $(63,69 \mu \mathrm{m})$ and DMLS $(64,27 \mu \mathrm{m})$. According to the four-unit FPDs results of the this study, before porcelain firing stage, mean marginal fit values were similar in all groups; $\operatorname{LW~}(68,72$ $\mu \mathrm{m}), \mathrm{MM}(71,70 \mu \mathrm{m})$ and DMLS $(70,42 \mu \mathrm{m})$. After porcelain firing stage, mean marginal fit value of DMLS $(71,64 \mu \mathrm{m})$ was slightly higher than $\operatorname{LW}(65,70 \mu \mathrm{m})$ and $\operatorname{MM}(61,95 \mu \mathrm{m})$.

In the literature, there were a lot of in vitro investigations $(10,13,15,20,37)$ which were evaluated and compared the marginal fit changes of metal-ceramic crowns fabricated with different techniques. Unfortunately, there were limited study with three-units $(1,5,14)$ and few study [40] with four-unit. FPD's. Örtrop et al. (5) evaluated and compared the marginal and internal fit of three-units FPD's in Cr-Co fabricated by LW, milled wax with lost-wax (MW), MM and DLMS' techniques before the PFC. Best fit was found for DMLS group $(84 \mu)$, followed by MW $(117 \mu)$; LW (133 $\mu)$ and MM (166 $\mu)$. These results were parallel with the presented studies results. The MM groups $(82.74 \mu)$ results were higher than the DMLS groups $(63.97 \mu)$ which was the lowest mean marginal gap values obtained. Örtrop et al. (5) reported the highest values for MM groups $(166 \mu)$, nerveless in the presented study LW group $(98.68 \mu)$ results were higher than all the other groups. The reason for this discrepancy could be related to the milling machine which manufacturers were different. And also, Örtrop et al. (5) used $50 \mu$ 's cement thickness, but in the presented study $30 \mu$ 's die spacer was applied as a cement thickness. Olivera and Saito (41) reported that the thickness of the die spacer could be affecting the adaptation of the restorations. Kim et al. (14) compared and evaluated the marginal and internal gap of three-nits FPD's fabricated by using DMLS system with that of threeunit FDP's by a LW method and reported that the DMLS results $(130.6$ and $133.1 \mu)$ were higher than the LW results $(81.7$ and $81.8 \mu$ ).These results were not compatible with the presented study. Kim et al. (14) used epoxy resin model, but in this study stainless steel models were used. It may be the reason for this difference. Nesse et al. (1) examined and compared the internal and marginal fit of cobalt-chromium metal frameworks of three-unit FPD's fabricated by LW, MM and selective laser melting (SLM). Direct-sight technique was used to evaluate the marginal fit. Scored 1-5 was used and they reported that the MM group had the best overall fit, followed by the LW and SLM groups. These results were parallel with the initial results of the presented study, before the PFC the mean marginal gap values of the MM technique were lower than the others.

In the literature, there were no study which compare the marginal adaptation of MM and DMLS methods. Bayramoglu et al. (40) was compared the marginal and internal marginal fit of three different restorative materials and the effect of veneering/pressing on the material used for 3 - and 4 unit implant supported FPDs. The mean marginal gap values obtained were75.4 $\mu \mathrm{m}$ Mand $103.82 \mu \mathrm{m}$ for the three and four unit FPD's fabricated by LW respectively. The four-unit's mean marginal values were higher than the three-unit's. In the presented study, the results were $64.58 \mu \mathrm{m}$ and 65.70 $\mu \mathrm{m}$ respectively. There were a slight difference between the results, but all the values were in clinically acceptable level.

In the presented study, statistically significant decrease was observed for the mean marginal gap values in three-units LW and in three and four units MM group after porcelain firing cycles ( $p: 0.000)$. The results of the four units LW and three or four units DMLS group were changed slightly and no statistically significant difference was found. Sundar et al. (10) reported similar results after ceramic firing with Co-Cr alloy copings fabricated by DMLS, the change was not statistically significant.

In the literature, no consensus exists on the effect of ceramic firing cycles on the marginal fit of FDPs (18). Quante et al. (8) reported that the ceramic firing changed the gap of the crown slightly. These changes, increasing or decreasing the marginal gap after ceramic firing, support the idea that the porcelain firing cycles distorts the metal substructure (17). In the literature, previous study $(42,43)$ were in agreement in two areas, first of all the distortion occurs during the thermal cycling process and second one the timing of the deformation mostly occurs during the oxidation of the alloy. Patil et al. (44) observed that small changes continue during the porcelain application process. The results of the presented study show that the ceramic firing cycles changed the marginal gap of the three and four-unit FPD's manufactured by LW, MM and DMLS's techniques. The gap values were decreased after PFP for LW and MM, slight increase were seen in DMLS's group. The minimum and maximum mean marginal gap values obtained were in $61.95 \mu \mathrm{m}$ and $71.64 \mu \mathrm{m}$ range. Fortunately all the marginal gap values obtained were in clinically acceptable level. Therefore, the three methods tested in this study, LW, MM and DMLS, could be used safely in the clinic with regard the marginal gap values. Further clinical study is needed to evaluate the survival of these new techniques as MM and DMLS. 


\section{CONCLUSION}

Within the limitations of this study, it can be concluded that PFC decreases the mean marginal gap of the LW and MM group, but, there were a slight increase for DMLS group. However, all the marginal gap values of all tested techniques were in clinical acceptance level for three and four-units FPD's after PFC.

\section{REFERENCES}

[1] Nesse H, Ulstein DM, Vaage MM, Qilo M. Internal and marginal fit of cobalt chromium fixed dental prostheses fabricated with 3 different techniques. J Prosthet Dent. 2015;114(5): 686-692.

[2] Ushiwata O, Moraes JV. Method for marginal measurements of restorations: Accessory device for toolmakers microscope. J Prosthet Dent. 2003;83: 362-366.

[3] McLean JW, von Fraunhofer JA. The estimation of cement film thickness by an in vivo technique. Br Dent J. 1971;131(3): 107111.

[4] Goldin EB, Boyd NW, Goldstein GR, Hittelman EL, Thompson VP. Marginal fit of leucite-glass pressable ceramic restorations and ceramic pressed-to-metal restorations. J Prosthet Dent. 2005;93: 143-147.

[5] Örtorp A, Jönsson D, Mouhsen A, von Steyern PV. The fit of cobalt - chromium three-unit fixed dental prostheses fabricated with four different techniques: A comparative in vitro study. Dent Mater. 2011;27: 356-363.

[6] Ucar Y, Akova T, Akyil MS, Brantley WA. Internal fit evaluation of crowns prepared using a new dental crown fabrication technique: laser-sintered $\mathrm{Co}-\mathrm{Cr}$ crowns. J Prosthet Dent. 2009;102(4): 253-259.

[7] Kane LM, Chronaios D, Sierraalta M, George FM. Marginal and internal adaptation of milled cobalt-chromium copings. J Prosthet Dent. 2015;114(5):680-685.

[8] Quante K, Quintas AF, Oliveira F, Bottino MA. Vertical marginal discrepancy of ceramic copings with different ceramic materials, finish lines, and luting agents:an in vitro evaluation. J Prosthet Dent. 2004;92(3): 250-257.

[9] Akova T, Ucar Y, Tukay A, Balkaya MC, Brantley WA. Comparison of the bond strength of laser-sintered and cast base metal dental alloys to porcelain. Dent Mater. 2008; 24(10):14001404.

[10] Sundar MJ, Chikmagalur SB, Pasha F. Marginal fit and microleakage of cast and metal laser sintered copings-An in vitro study. J Prosthodont Res. 2014;58: 252-258.

[11] Persson A, Andersson M, Oden A, Sandborgh-Englund G. A three-dimensional evaluation of a laser scanner and a touchprobe scanner. J Prosthet Dent. 2006; 95(3):194-200.

[12] Gonzalo E, Suarez MJ, Serrano B, Lozano JF. A comparison of the marginal vertical discrepancies of zirconium and metal ceramic posterior fixed dental prostheses before and after cementation. J Prosthet Dent. 2009;102: 378-384.

[13] Xu D, Xiang N, Wei B. The marginal fit of selective laser melting fabricated metal crowns: an in vitro study. J Prosthet Dent. 2014; 112(6):1437-1440.

[14] Kim KB, Kim WC, Kim HY, Kim JH. An evaluation of marginal fit of three-unit fixed dental prostheses fabricated by direct metal laser sintering system. Dent Mater. 2013a;29(7): 91-96.
[15] Kim KB, Kim JH, Kim WC, Kim HY, Kim JH. Evaluation of the marginal and internal gap of metal-ceramic crown fabricated with a selective laser sintering technology: two - and threedimensional replica techniques. Adv Prosthodont. 2013b;5(2): 179-186.

[16] Kane LM, Chronaios D, Sierraalta M, George FM. Marginal and internal adaptation of milled cobalt-chromium copings. J Prosthet Dent. 2015; 114(5):680-685.

[17] Gemalmaz D, Alkumru HN. Marginal fit changes during porcelain firing cycles. J Prosthet Dent. 1995;73: 49-54.

[18] Kunii J, Hotta Y, Tamaki Y, Ozawa A, Kobayashi Y, Fujishima A, Miyazaki T, Fujiwara T. Effect of sintering on the marginal and internal fit of CAD/CAM-fabricated zirconia frameworks. Dent Mater J. 2007;26(6):820-826.

[19] van Noort R. The future of dental devices is digital. Dent Mater. 2012;28:(1): 3-12.

[20] Park JK, Kim HY, Kim WC, Kim JH. Accuracy evaluation of metal copings fabricated by computer-aided milling and direct metal laser sintering systems. J Adv Prosthodont. 2015;7(2): 122128.

[21] Vigolo P, Fonzi F. An in vitro evaluation of fit of zirconium-oxidebased ceramic four-unit fixed partial dentures, generated with three different CAD/CAM systems, before and after porcelain firing cycles and after glaze cycles. J Prosthodont. 2008;17(8): 621-626.

[22] Regish KM, Sharma D, Prithviraj DR, Nair A, Raghavan R. Evaluation and comparison of the internal fit and marginal accuracy of base metal (nickelchromium) and zirconia copings before and after ceramic veneering: a sem study. Eur J Prosthodont Restor Dent. 2013;21(1):44-48.

[23] Souza RO, Ozcan M, Pavanelli CA, Buso L, Lombardo GH, Michida SM, Mesquita AM, Bottino MA. Marginal and internal discrepancies related to margin design of ceramic crowns fabricated by a CAD/CAM system. J Prosthodont. 2012;21(2): 94-100.

[24] Tsitrou EA, Northeast SE, van Noort R. Evaluation of the marginal fit of three margin designs of resin composite crowns using CAD/CAM. J Dent.2007;35(1): 68-73.

[25] Yeo IS, Yang JH, Lee JB. In vitro marginal fit of three all ceramic crown systems. J Prosthet Dent. 2003;90(5): 459-464.

[26] Suarez MJ, Gonzalez de Villaumbrosia P, Pradies G, Lozano JF. Comparison of the marginal fit of Procera AllCeram crowns with two finish lines. Int J Prosthodont. 2003;16(3): 229-232.

[27] Wolfart S, Wegner SM, Halabi A, Kern M. Clinical Evaluation of Marginal Fit of a New Experimental All-Ceramic System Before and After Cementation. Int J Prosthodont. 2003;16:587-592.

[28] Holden JE, Goldstein GR, Hittelman EL, Clark EA. Comparison of the marginal fit of pressable ceramic to metal ceramic restorations. J Prosthodont. 2009;18(8):645-648.

[29] Fonseca JC, Henriques GE, Sobrinho LC, de Góes MF. Stressrelieving and porcelain firing cycle influence on marginal fit of commercially pure titanium and titanium-aluminumvanadium copings. Dent Mater 2003;19(7):686-691.

[30] Groten M, Axmann D, Probster L, Weber H. Determination of the minimum number of marginal gap measurements required for practical in-vitro testing. J Prosthet Dent. 2000;83(1): 4049.

[31] Nawafleh NA, Mack F, Evans J, Mackay J, Hatamleh MM. Accuracy and Reliability of Methods to Measure Marginal Adaptation of Crowns and FDPs: A Literature Review. J Prosthodont. 2013;3: 97-111. 
[32] Quante K, Quintas AF, Oliveira F, Bottino MA. Vertical marginal discrepancy of ceramic copings with different ceramic materials, finish lines, and luting agents: an in vitro evaluation. J Prosthet Dent. 2004;92(3): 250-257.

[33] Coli P, Karlsson S. Fit of a new pressure sintered zirconium dioxide coping. Int J Prosthodont. 2004;17: 59-64.

[34] Reich S, Gozdowski S, Trentzsch L, Frankenberger R, Lohbauer $U$. Marginal fit of heat-pressed vs. CAD/CAM processed allceramic onlays using a milling unit prototype. Oper Dent. 2008;33(6): 644-650.

[35] Laurent M, Scheer P, Dejou J, Laborde G. Clinical evaluation of the marginal fit of cast crowns-validation of the silicone replica method. J Oral Rehabil. 2008;35(2): 116-122.

[36] Bugurman BB, Turker SB. Clinical gap changes after porcelain firing cycles of zirconia fixed dentures. J Adv Prosthodont 2014;6:177-184.

[37] Harish V, Mohamed Ali SA, Jagadesan N, Mohamed I, Siva S, Debasish B, Febel H. Evaluation of Internal and Marginal Fit of Two Metal Ceramic System - In Vitro Study. J Clin Diagn Res. 2014;8(12): 53-56.
[38] Bindl A, Windisch S, Mormann WH. Full-ceramic CAD/CAM anterior crowns and copings. Int J Comput Dent. 1999;2: 97-111.

[39] Christensen GJ. Marginal fit of gold inlay castings. J Prosthet Dent. 1966;16(2):297-305.

[40] Bayramoglu E, Ozkan YK, Yıldız C. Comparison of marginal and internal fit of press-on-metal and conventional ceramic systems for three - and four-unit implant-supported partial fixed dental prostheses:An in vitro study. J Prosthet Dent 2015;114:52-58.

[41] Olivera AB, Saito T. The effect of die spacer on retention and fitting of complete cast crowns. J Prosthodont 2006;15(4):243-249.

[42] Bridger DV, Nicholls JI. Distortion of ceramoometal fixed partial dentures during the firing cycle. J Prosthet Dent 1981;45:507-510.

[43] Dehoff PH, Annusavice KJ. Effect of metal design on marginal distortion of metal ceramic crowns. J Dent Res;1984;63:1327-1332.

[44] Patil A, Singh K, Sahoo S, Suwarma S, Kuman P, Singh A. Comparative assessment of marginal accuracy of grade II titanium and $\mathrm{Ni}-\mathrm{Cr}$ alloy before and after ceramic firing: $\mathrm{An}$ in vitro study. Eur J Dent 2013;7:272-277. 